\title{
Family caregiver of older adults and Cultural Care in Nursing care
}

\author{
Cuidador familiar de idosos e o Cuidado Cultural na assistência de Enfermagem \\ Cuidador familiar de ancianos y el Cuidado Cultural en la asistencia de Enfermería
}

\section{Alcimar Marcelo do Couto', Célia Pereira Caldas", Edna Aparecida Barbosa de Castro'}

' Universidade Federal de Juiz de Fora, School of Nursing. Juiz de Fora, Minas Gerais, Brazil

"Universidade do Estado do Rio de Janeiro. Rio de Janeiro, Brazil.

\begin{abstract}
How to cite this article:
Couto AM, Caldas CP, Castro EAB. Family caregiver of older adults and Cultural Care in nursing care. Rev Bras Enferm [Internet]. 2018;71(3):959-66. DOI: http://dx.doi.org/10.1590/0034-7167-2017-0105
\end{abstract}

\section{Submisison: 04-04-2017 Approval: 05-17-2017}

\begin{abstract}
Objective: To analyze the experiences of family caregivers of dependent older adults, who show performance overload and emotional distress, using the Theory of Culture Care. Method: Qualitative study with nine caregivers of home care dependent older adults, based on Grounded Theory. Results: The findings allowed the identification of potentialities and frailties in the context of family home care and subsidizing the construction of a theoretical scheme resulting from the analysis of possibilities of the nursing care practice according to the culture, through the three modes of action: maintenance, adjustment and repatterning of cultural care. Final considerations: Respecting the cultural values and family beliefs, the nurse can help to institute mutually established changes, promoting a better quality in the nursing care relationship and a relief to the strain of the role of the caregiver.
\end{abstract}

Descriptors: Caregivers; Family; Older Adult; Nursing Theory; Culture.

\section{RESUMO}

Objetivo: Analisar as experiências de cuidadores familiares de idosos dependentes, que apresentam sobrecarga e desconforto emocional, à luz da Teoria do Cuidado Cultural. Método: Estudo qualitativo, fundamentado na Grounded Theory, com nove cuidadores de idosos dependentes de cuidados no domicílio. Resultados: Os achados possibilitaram identificar potencialidades e fragilidades no contexto familiar de cuidado domiciliar e subsidiaram a construção de um esquema teórico decorrente da análise das possibilidades de atuação da enfermagem mediante um cuidado congruente com a cultura, através dos três modos de ação: manutenção, ajustamento e repadronização do cuidado cultural. Considerações finais: Respeitando os valores culturais e as crenças da família, o enfermeiro pode ajudar a instituir mudanças, coestabelecidas com os cuidadores, que promovam uma melhor qualidade na relação de cuidar e aliviem a tensão do papel de cuidador.

Descritores: Cuidadores; Família; Idoso; Teoria de Enfermagem; Cultura.

\section{RESUMEN}

Objetivo: Analizar las experiencias de los cuidadores familiares de los ancianos dependientes, que presentan sobrecarga e incomodidad emocional, a la luz de la Teoría del Cuidado Cultural. Método: Estudio cualitativo, fundamentado en la Grounded Theory, con nueve cuidadores de ancianos dependientes de cuidados en el domicilio. Resultados: Los hallazgos posibilitaron identificar potencialidades y fragilidades en el contexto familiar de cuidado domiciliar y subvencionaron la construcción de un esquema teórico decurrente del análisis de las posibilidades de actuación de la enfermería por medio de un cuidado congruente con la cultura, a través de los tres modos de acción: el mantenimiento, el ajuste y la re-estandarización del cuidado cultural. Consideraciones finales: Respetando los valores culturales y las creencias de la familia, el enfermero puede ayudar a instituir cambios, coestablecidas con los cuidadores, que promuevan una mejor cualidad en la relación de cuidar y alivien la tensión del papel de cuidador.

Descriptores: Cuidadores; Familia; Anciano; Teoría de Enfermaría; Cultura. 


\section{INTRODUCTION}

The development of a base of knowledge and the recognition and definition of means to communicate it are requirements for a profession. Thus, any nursing practice needs theoretical foundations. The theory can offer a systematic way to view facts and events, and provide contribution to the research process, diagnosis, planning, implementation and evaluation of nursing ${ }^{(1-2)}$.

Serving as instruments to the various fields of nursing practice, the theories should guide research, teaching, management and care assistance. By developing theories and studying their applications in professional practice the status of science is enforced and the specific field of knowledge is widened ${ }^{(3)}$.

Care is a complex and multidisciplinary concept. Reflecting on the specificity of the concept, there are different existing definitions that explore various perspectives and complement each other. This study adopted the definition of Madeleine Leininger, who defines care as the actions and activities directed to the assistance, support or training of another individual or group with clear or anticipated needs, to improve the human condition, way of life or to face death ${ }^{(1,4)}$.

In the Theory of Culture Care Diversity and Universality, Leininger conceives the existence of social and cultural forces that exert important influences on human beings and, consequently, on the process of care. Considering this, health professionals should give more attention to the resulting attributes of culture. In the nursing field, the disregard for these factors in care practices, the looseness from the cultural reality of the person, the incongruity between the act of caring and their values and beliefs may result in the appearance of cultural conflicts, frustrations, stress and even moral and ethical concerns ${ }^{(3-5)}$.

This theory was represented by the Sunrise model. This model facilitates the understanding of the triad individualfamily-group when facing their cultural values and ways of life, being relevant to the nursing care by allowing the construction of complex and critical thinking about the dimensions of the cultural and social structures in each specific context ${ }^{(2,5-6)}$.

Composed of factors that relate to each other, interfering in the process of nursing care, the model is divided in four levels: 1 - it leads to the study of nature, significance and attributes of nursing care; 2 - it provides knowledge about the individuals, families, groups and institutions, in various health systems; 3 it focuses on the popular system, the professional system and, in it, nursing; 4 - it is the level of the decisions and actions of nursing care, which involves the cultural preservation/maintenance of care, cultural accommodation/negotiation of care and the cultural repatterning/restoration of care ${ }^{(2,5-6)}$.

We believe that the process of nursing care of dependent older adults at home by a family member has its own characteristics in different contexts, despite being an universal phenomenon observed in multiple nationalities and cultures. Having this as basis, the nursing care must be based on the theory of cultural care, being adequate to every individual or group, respecting their characteristics and using actions that are consistent with the values and the needs identified in each situation ${ }^{(2,5)}$.

This study is relevant when considering the rapid demographic and epidemiological transition in Brazil, which contributes to incite dependency relationships that interfere in the social interaction processes of older adults and create the need for family care $^{(7)}$.

Thus, analyzing the care provided by family members to older adults in need of assistance in Brazil, becomes extremely important to meet the needs and demands of this population. Through the cultural dimension of nursing care, the nurse avoids the nursing care practice as just empirical or technical, and performs a practice rooted in scientific and theoretical models. In the context of family caregivers of dependent older adults, the nurse needs to perform nursing care using family experiences, the sociocultural context of the family, considering nursing experiences from the culture in which the binomial older adult-caregiver is inserted ${ }^{(2)}$.

Based on this premise, we wondered: how the nursing theory of Culture Care Diversity and Universality could provoke reflections on the phenomenon "the life context and the experience of caring for dependent older adults in the home environment by family caregivers who show performance overload and emotional distress"?

Caring for dependent older adults might entail negative aspects to the relative, such as changes in physical and emotional state, imbalance between activity and rest, as well as compromised individual coping. These are the attributes of the strain placed on the caregiver, this is a significant aspect of our cultural care reality ${ }^{(8-11)}$. Given the context of performance overload and emotional distress of the family caregiver, knowing their psychosocial responses allows the understanding of how to plan for home care.

\section{OBJECTIVE}

To present an analysis of nursing care experiences done by overloaded and emotionally distressed family caregivers of dependent older adults at home, pointing to the implications for the practice of Nursing with the use of the Theory of Culture Care Diversity and Universality.

\section{METHOD}

\section{Ethical aspects}

The project met the recommendations of Resolution no. 466/2012, of the National Health Council, which regulates research involving human beings in Brazil. The survey was conducted with approval by the Research Ethics Committee of the University Hospital of UFJF. This study used precious and semi-precious stones as codenames for the participants to guarantee their anonymity.

\section{Theoretical-methodological framework and type of study}

This is a qualitative study using Grounded Theory ${ }^{(12)}$ as the method to understand the care process performed by family members with different sociocultural patterns.

The Theory of Cultural Care Diversity and Universality of Madeleine Leininger provided subsidies for this analysis through these concepts and assumptions: culture, cultural care, diversity of cultural care, universality of cultural care, vision of the world, 
environmental context, nursing, culturally congruent nursing care, maintenance of cultural care, adjustment of cultural care and repatterning of cultural care $^{(4-5)}$.

\section{Study scenario}

The research took place in two scenarios. It was initially focused on the Ambulatório de Geriatria e Gerontologia do Hospital Universitário da Universidade Federal de Juiz de Fora [Geriatrics and Gerontology Clinic of the University Hospital of the Federal University of Juiz de Fora], Minas Gerais - Brazil, serving as the place to identify older adults dependent of others for their Basic Activities of Daily Life (BADL) and their main caregivers during nursing appointments. The home of the binomial dependent older adult-family caregiver became the second scenario. The strategy adopted to collect data were home visits as a form of getting closer to, knowing and characterizing the caregivers as well as observing their work overload and emotional distress.

\section{Data collection and organization}

A total of 78 older adults were evaluated, the Katz index $^{(13)}$ was used to determine the degree of partial or important dependency on the BADLs. Of these, 27 older adults were identified. The main family caregiver of the dependent older adult was identified and evaluated for the presence of performance overload on the caregiver role, using the Zarit scale for assessing caregiver burden (Burden Interview) ${ }^{(14)}$ and for detecting emotional distress (Self Reporting Questionnaire - SRQ-20) ${ }^{(15)}$.

After identifying the performance overload and emotional distress levels of the relatives, those who presented moderate, or moderate to severe performance overload and scores above the cutoff point for emotional distress in the SRQ-20 scale were selected to participate in the qualitative phase of the study, which occurred between August 2012 and March 2013, period in which this article was written. Twelve (12) caregivers met the inclusion criteria. Semi-structured interviews and participant observation were done during the home visits, field journals were made for nine of these caregivers, noting the theoretical saturation.

Data were collected after signing the Informed Consent Form, in one or two meetings, by appointment and prior consent.

The field notes were recorded as topics in a diary during the observation period and later expanded in the form of memos. The transcripts of the interviews and the pre-analysis were done after expanding the notes and before the next interview, starting the processes of open, axial and selective encoding, as pointed by the methodology ${ }^{(12)}$.

\section{Data analysis}

The emerging content were transcribed and analyzed as proposed by the Grounded Theory method, by open, axial and selective encoding. Through this process a group of codes in subcategories were obtained and then, categories according to concepts that led to the reflection of the phenomenon "the life context and the experience of caring for dependent older adults in the home environment by family caregivers who show work overload and emotional distress." The context-focused intervening conditions allowed the further analysis through the Theory of Culture Care Diversity and Universality of Madeleine Leiniger.

\section{RESULTS}

It was possible to identify the potentialities and frailties described in the four categories formed to explain the phenomena through the observation in the homes of families who live and care for a dependent older adult and through the interviews conducted with the main caregivers. The four categories are: becoming a caregiver; the experiences of being a caregiver for a dependent older adult; demands resulting from the process of nursing care for a dependent older adult by a family member; and search for support and training.

\section{Potentialities in the context of home care for the depen- dent older adult}

An identified potentiality was the prior experience with the process of care, by performing as the caregiver to other family members or even volunteer work. This characteristic outstood as a facilitating aspect for the adaptation to the routine of care that needs to be provided to the current dependent family member.

I had taken care of older adults already, bathed, fixed their hair, helped them with dressing, made the bed, did laundry. They were known, [...] it was voluntary. That helped me a lot. (Ruby)

However, they reported that numerous difficulties were faced in the initial phase of the caregiver role - fear, insecurity and inexperience were frequent. Over time, the relatives experienced relief of those feelings and scenarios, the emergence of adapting to their new life condition was noted, which facilitated their perception and identification of resources to overcome the obstacles. The caregivers, through their continuous care experiences, consolidated the experience and gradually adapted to the needs and routines of the older adult required by nursing care. This led to the adaptation and establishment of an empirical process of care. Thus, strategies were created such as delegating responsibilities to other family members to minimize the overload and emotional distress feelings as well as avoiding suffering.

I was getting used to it. [...] But this initial phase was very [emphasis] difficult. (Jade)

So, if I have to leave, I ask someone to look for her for me. I'm actually delegating now. [...] I didn't do that before. It was all me. (Sapphire)

Positive feelings, such as affection, solidarity, appreciation of their actions, in addition to moments of harmonious interaction between the caregiver and the older adult, emerge from the continuous caring experiences, which can be identified on the reports given by the caregivers. We comprehend these feelings as fundamental to the maintenance of the self-esteem 
of the caregiver, even facing the difficulties resultant from the commitment to the health condition of the relative.

My feeling is... Of wanting good things for that person, to see what I can do to help, and if I can help I'll be happy. And for my limitations, what I can do makes me happy, it's not even for taking care of an older adult, it's the possibility that I'm dodging my own disease, and that by helping someone else I am helping myself. (Crystal)

The existence of stimuli in the everyday life of the care relationship is also identified such as the support of secondary caregivers and the possibility of delegating some activities to other family members. The existence of support, especially financial, was identified as well as the direct collaboration in the care for the older adult.

So, if I need to leave, they stay here to take care of her. (Emerald)

I have a sister who helps me by paying a person to help me take care of her during the day. (Agate)

Yes, they financially help me. (Tourmaline)

It was possible to identify through the experiences with the caregivers in nursing appointments and the home visit followed by interview for this study, movements of support and professional support seeking the forming of a social support network, the start or increase in frequency of the search of religiousness/ spirituality as major strategies to keep performing the task of caring. These actions were aimed at the minimization of the negative effects caused by the stress in the role of caregiver.

I seek strength, especially on my therapist. I talk a lot with her, especially. (Crystal)

Here I call a neighbor and she helps me, you see? Any time that I come here in the fence [...] I call a neighbor they are willing to help me. (Crystal)

I allow God to take control and He gives me strength and... Then, the support I seek in God, because my support is in Him. Fully in God. (Emerald)

My support is in God. I touch my rosary and pray. [...] Then, I talk to my saints that help. When I am sad and facing difficulties I pray. (Ruby)

\section{Frailties in the context of home care of the dependent} older adult

The loss of autonomy and independence of older adults was mainly related to the emergence and evolution of chronic diseases. Dementia profiles were diagnosed in six of the nine dependent older adults cared by the participants of this study.

The changes caused by these profiles (such as cognitive deficit and the loss of memory and identity), on the perception of the surveyed caregivers, is that they make them feel anguish, pain, sadness, anger and even depression, showing a difficulty in accepting the process of family dependency of the older adult.
I am more depressed nowadays [...] sometimes I'm hit by revolt, then, when I see, I start crying. (Tourmaline)

We suffer [...]. It is a disease [referring to Alzheimer] that I'm going to tell you, I've got a chance to talk to a person, this disease is worse than cancer, because it takes even the dignity and the identity of the person. [...] it's sad, taking the identity of the person, right? (Sapphire)

Another difficulty reported by the caregivers was the absence of prior experience with the process of care. When caregivers became aware of the responsibility that was dropped into them, when all the basic and instrumental daily care needs of the relative became their responsibility, they felt threatened by lack of knowledge or skills, especially to perform some activities such as bathing, diaper change and administration of medications.

I'd never given a bath, I'd never taken care of someone sick. (Jade)

Today I take care of everything, I change diapers, I go after medical prescriptions so I can buy less expensive diapers using the government program, you see. [...] In this part, to care of hospital, of doctor, of medicine, of bath, of food, everything, I'm the one doing it, but at the beginning it was very difficult. (Emerald)

We observed that the formation of the role of main caregiver was accompanied by impacts on various aspects of life and health, causing a series of limitations and difficulties for their lives. According to the participants, the higher risks of getting ill, self-negligence, performance overload and emotional distress are caused in part by the uncertainties and the dilemmas in the family relations, and for the most part, the absence of an established support network of family members. The lack of days or moments off and the absence of relay of the care activities between family members are examples.

\section{My biggest difficulty is the lack of support within the fam- ily. (Crystal)}

So, it was very hard. Not having anyone to share the responsibility. (Jade)

I take care of her every day, weekends, Saturday, Sunday, holiday, there are no breaks or days to rest. (Tourmaline)

According to the reports of the participants, the routine experience of nursing care of dependent older adults can be understood as the set of changes that happened in their lives from the moment when the need to take such care took place. In the initial context, caregivers reported that the love life started to occupy a secondary plan, they had to leave work to take care of the family member, in addition to the loss of commitment with social activities such as leisure activities and changes in their health conditions. Changes in the health conditions include changes in the usual pattern of sleep, with a reduction of time and quality, because of the constant interruptions. 
Daily moments of rest became nonexistent or minimal, in addition to the coexistence with negative feelings.

My leisure was fully "pruned," because I cannot find anyone to be with her. [...] I don't have freedom to take a walk or to have an hour for lunch. So, I abandoned entirely my leisure, for her. (Crystal)

I already sleep very little. [...] I've been sleeping, but even with the littlest movement I'm awake. I watch her at night, if she is breathing and everything, I already have it, this fear. (Pearl)

As the dependency advances, progressive changes in the daily lives of families happen, especially in the course of life of the main caregiver. The routine of care was shown to be pervaded by diverse and contradictory feelings such as fear, sadness, insecurity, concern, conflicts and tensions. Fear was a very common sentiment and it was related to several factors, being evidenced by the fear of "the degree of dependence" of the older adult getting worse and this representing an increase in the already high demand for care given by the caregiver.

We are afraid she will get even worse. How are we going to do? It's going to be even more difficult. (Pearl)

[...] I'm scared to death of her getting worse and not being able to handle it. (Jade)

Some repercussions in the dynamics of life arising from the process of caring for the dependent older adult were highlighted by the participants: the family conflict permeated by disputes and accusations; the lack of time for self-care and maintenance or involvement in social activities; and those of economic nature, with suppression of spending with themselves, given the increase in expenses with the older family member.

[...] To be able to hospitalize her I have the family thinking badly of me. Half the family dislikes me, because I fought to go with her to the hospital. (Crystal)

I cannot fix things right, because who handles sick people cannot handle everything [...] I lack time to do everything, I can only take care of him. There is no time to think of me. (Ruby)

We live in the grace of God, because there is no more room on my budget. [...] But then we get through very tight. [...] The number of diapers has increased, the number of remedies that are purchased [...] So there is a financial burden and I think that also wears me [...]. (Sapphire)

We should highlight that the costs of the care fall upon the family, especially those with low income and that live with dementia, wounds or any other injury that requires therapy and specific technologies, not always available at the health system. In addition to the social and emotional costs, the financial cost consumes the resources that the caregivers used to invest in themselves. This factor requires further study to detail the costs of family caring for dependent older adults.

\section{Implications for Nursing}

The in-depth study of the phenomenon "the life context and the experience of caring for dependent older adults in the home environment by family caregivers who show performance overload and emotional distress" from the theoretical framework of Culture Care Diversity and Universality of Leiniger made the construction of a theoretical scheme possible. Derived from the analysis of possibilities of culturally congruent nursing care, through the three modes of action: adjustment (adaptation/negotiation), preservation/maintenance and repatterning/restructuring of culture care.

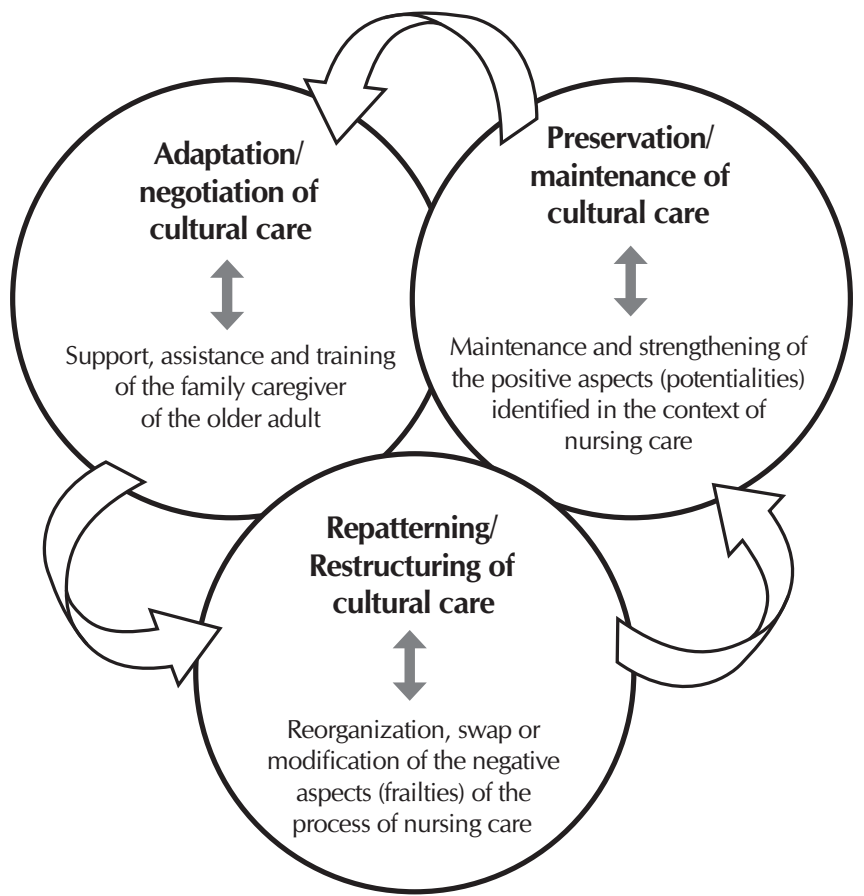

Figure 1 - Conceptual Diagram: the older adult caregiver, nursing and cultural care

\section{DISCUSSION}

Nursing assistance in situations of chronic or irreversible dependency, comprehended using the Theory of Cultural Care Diversity and Universality, brings attributes that the professional should prioritize instead of chasing the cure, which is not always possible, focusing on care, which is an essential human need. Through cultural care, the nurse adopt in these cases one of the assumptions of the theory: "cure is impossible without care, but there may be care even with no possibility of cure" ${ }^{\prime \prime 1,4)}$.

In scenarios in which the cure of pathological processes is impossible, as in the cases of dementia or the reversal of the dependency, it is up to nursing and the family caregiver to provide the required care so the older adult, in its limitations, is taken care of. The development of coping strategies to overcome the negative feelings can be stimulated. These feelings might be originated from a cultural way of relating to living together and having to take care of a dependent older adult and in need of home care from the family ${ }^{(2,4)}$. 
Professional investment on nurse care according to the cultural dimension becomes relevant to change the scenario of suffering that is established through the continuous life of the caregivers, who take high loads of activities resulting from the dependency process of the older relative ${ }^{(2)}$.

Potentialities and frailties that influence the intensity of the overload and emotional distress levels of the family caregivers were identified along the studied sociocultural context of the formation of the caregiver role. The formation period seems to be a moment in which the families need monitoring and support from health professionals and from a support network, this would enforce the positive aspects while minimizing or eliminating the negative aspects identified ${ }^{(16)}$.

The prior experience with the process of nursing care and the support from secondary caregivers who contribute sharing the daily activities are some of the potentialities identified. Prior experience in other care situations contributes to the change of posture and attitude as the main caregiver facing the new nursing care relationship, since some relatives realize the need for the division of responsibilities and the need to allow the involvement of other family members. Strategies of coping or support should be identified or stimulated and supported, in such a way caregivers can periodically relieve themselves of the responsibilities and requirements inherent to the care process ${ }^{(10)}$. Actions in this sense contribute to eliminate or reduce the emergence of morbidities and comorbidities in the binomial dependent older adult-family caregiver.

We also observed that caregivers carry culturally constructed values and habits related to family roles, once they start caring for a sick or dependent family member. In addition to the bonds and interaction between the caregiver and the dependent older adult acting as positive stimuli that facilitates the performance of nursing care and contributing to relieve the tension of the caregiver, another important factor is the ability to maintain the self-esteem of the caregiver and the support and family bonding, even when facing series of difficulties and limitations in daily life of caring ${ }^{(10,17)}$.

In the search for support and as a form of dealing with the negative aspects of the nursing care relation, religiousness/ spirituality were pointed as an important strategy adopted by caregivers. Faith, spirituality and religious practices were cited and identified, also being used by families assessed by other studies, which consider them as very effective coping strategies to deal with stress, anguish, depression and overload resultant from the nursing care process. We understand that the caregivers seek help through the expressions of religioiusness/ spirituality to obtain the strengthening of hope, comfort and relief of suffering, establishing itself as a protective factor ${ }^{(17-18)}$.

We reinforce that this set of positive aspects found in the nursing care relationship established in family environments needs to be recognized, respected and valued by the nurses during the proposed guidance and support activities. By assuming this theoretical thought as part of the nursing practice the nurse could possibly adopt the principle of preservation/maintenance of cultural care ${ }^{(4-}$ ${ }^{5)}$ to help maintain and strengthen: positive feelings, prior experience of the caregiver, adaptation to a cultural process of nursing care, interaction in the caring relationship and maintenance of the self-esteem of the caregiver. The expected result is the preservation of the health conditions of the caregiver, the ability to perform its role and thus, the promotion of mutual well-being.

Feelings of agony, sadness, fear, anger, insecurity and worry experienced routinely and long term can contribute to the wear on the caregiver role ${ }^{(18)}$. Thus, families need professional support in these situations, in such a way they can organize and establish a care routine involving the greatest possible number of family members or even friends and neighbors. This support helps the main caregivers to maintain their social activities, self-care, leisure and rest, without feeling guilty or insecure with the ability to care of the other subjects involved in the process ${ }^{(2,17)}$.

The situations experienced in the nursing care process demonstrate the lack of skills and appropriate training to perform the role. Additionally, they point to the need of support actions for family caregivers and even health education to provide better conditions of nursing care for the dependent older adult population, meeting the specific knowledge and skills necessary for the family caregivers to perform the actions delegated to them ${ }^{(19)}$. Preparing and accompanying the relative in the performance of the new caregiver role is needed, helping them to overcome difficulties and to provide quality nursing care that meets all the identified needs and that is congruent with the cultural context of the family group ${ }^{(3)}$.

The way each family member performs the daily care depends on the acquired and practiced knowledge, it can be said that the nursing care actions reflect the culture of the caregiver, its family and their context. Therefore, culture determines the patterns and lifestyles, influencing the decisions made, which determines that the nurse performs care based on the culture of the subjects ${ }^{(2,5)}$.

The noticeable lack of guidelines and support from health services were identified as a contributing factor to the emergence of overload and emotional distress feelings by the caregiver. Considering the increased demand of time and the insecurities when facing difficulties in nursing care activities without the necessary knowledge for each scenario experienced ${ }^{(2)}$.

The difficulty of the caregiver in obtaining support in the share of nursing care tasks is related to insertion into reduced family size or because other family members work, but also due to the lack of involvement of other relatives in the dependency situation of the older adult, health problems and even the difficulty of the main caregiver in trusting in the ability of other family members to perform the function. The impossibility of sharing the nursing care activities with other relatives is a determining factor for the definition and often, for the lonely maintenance of the main caregiver ${ }^{(2,10,20)}$.

Observing the everyday life of caregivers of older adults allowed us to note that nursing care is a demanding task that causes many changes in their lives after taking the role, such changes include the abandonment of work and the economic impact on family dynamics, the lack of time for social activities (mainly leisure activities) and effects on physical and mental health conditions, with frequent reports of changes in the sleep pattern ${ }^{(16-17,20)}$. Not sleeping well or sleeping too little reflects on the performance of everyday activities, on behavior and on the well-being feeling ${ }^{(2)}$.

Family caregivers have shown concern for failing to take proper care of their health conditions and reported difficulty 
in accommodating the activities as a caregiver and self-care, the greater difficulty is the lack of family support and of social and health support networks. Sometimes the family members realize that they are living on the limits of their physical and emotional reserves, but have no one to help. In other cases, the involvement in the nursing care process is so deep that they do not realize that the limits of their conditions to provide care have been reached, sometimes exceeding these limits ${ }^{(18,20-21)}$.

Main caregivers need the help of other family members and to set days and times for each to assume part of the care processes and responsibilities. This partnership allows them to have time available to take care of themselves, to have leisure periods and to recover the energy spent when taking care of the other, minimizing the strain on the performed role.

The charges in relation to the main caregiver role, the lack of understanding and support from other family members and family disputes, in addition to to the economic repercussions caused by low income families, the abandonment of work to be devoted entirely to the caregiver role and the increase in expenditure because of the demands of the nursing care process of the older adult, are contributing factors to the nursing diagnosis stress in the role of caregiver ${ }^{(8-9,22-23)}$.

Given this context of negative aspects experienced by the family caregiver, which cares for the dependent older adult in the home environment, the nurse can adopt the accommodation/negotiation and repatterning/restructuring of cultural care methods. The first involves actions directed at the forms or ways to negotiate, adapt and adjust the identified adverse conditions, the second refers to nursing actions that seek to assist the caregiver of older adults in the modification process of the negative patterns ${ }^{(1,4)}$, such as the abandonment of work to nurse care, leisure, love life being in the background, negative feelings in the care process, compromising of their health conditions and changes in sleep and rest patterns to patterns that are beneficial to the family caregiver and the relationship of care.

\section{Study limitations}

This study was limited to the experiences of a group of family caregivers who had experienced the overload resulting from the care of a dependent older adult relative. A limitation of this research, inherent to the method, refers to the fact that data analysis has not been done independently by two researchers. Being a current and relevant theme to the daily practice of nurses from different areas, it is suggested that the issue be investigated through other methods that allow a greater generalization.

Other question that arise and that will require further research through different methods relate to the sleeping pattern of the family caregiver, religiousness/spirituality as therapeutic support, the expenses of the family with the home care of dependent older adults and how the nurse is present in home care teams, adopting the culturally congruent nursing care.

\section{Contributions to the field of Nursing}

The use of Theory of Culture Care Diversity and Universality of Madeleine Leininger contributed to the reflection about the possibilities of nursing performance on the context experienced by family caregivers of dependent older adults. From the perspective of cultural care, the nurse could contribute to these families using the three modes of action proposed by Leininger -preservation/maintenance, adjustment/ negotiation and repatterning/restructuring of culture care -, thus providing nursing care better suited to the culture of the older adult/caregiver/family.

\section{FINAL CONSIDERATIONS}

The obtained results enabled us to know and understand the experiences when taking care of dependent older adults at home by a family caregiver who presented performance overload and emotional distress in the role. The methodological approach used contributed to better approach the sociocultural reality of each family, to observe the daily life of the main caregiver and to establish trust, which enabled dialogue marked by emotions and relief, and reports that expressed their difficulties, limitations, needs and potentialities.

We recommend that the potentialities and frailties that stem from the process of home care of dependent older adults are recognized, picking up the values and the beliefs of the family and the sociocultural context of the family caregiver. This would enable the structuring of interventions and care plans, designed from the nursing consultations, home visits and educational activities such as groups of older adult caregivers congruently with the cultural attributes. These are possibilities that help to institute mutually established changes with caregivers, promoting better quality of family relationships of care and relieving the strain of the caregiver role.

\section{REFERENCES}

1. George JB. Theory of culture care diversity and universality: Madeleine M. Leininger. In: Nursing Theories: the Base for Professional Nursing Practice. 6th ed. United States of America: Pearson Education Limited; 2014.

2. Ramos JLC, Menezes MR. Elderly care with alzheimer disease: a focus on the theory of cultural care. Rev Rene [Internet]. 2012[cited 2017 Jan 20];13(4):805-15.Available from: http://www.revistarene.ufc.br/revista/index.php/revista/article/view/1075/pdf

3. Seima MD, Michel T, Méier MJ, Wall ML, Lenardt MH. Scientific nursing production and Madeleine Leininger's theory: integrated review 1985 - 2011. Esc. Anna Nery Rev Enferm[Internet]. 2011[cited 2017 Jan 25];15(4):851-57. Available from: http://www. scielo.br/pdf/ean/v15n4/a27v15n4.pdf

4. Leininger MM. Culture care diversity and universality: a theory of nursing. National League for Nursing. New York: Jones Bartlett Publishers; 2001. 
5. Fortes AFA, Soane AMN, Braga CGB. Teoria do cuidado cultural ou diversidade e universalidade do cuidado cultural - Madeleine Leininger. In: Silva JV, (Org.). Teorias de enfermagem. São Paulo: Látria; 2011. p.155 -180.

6. Melo LP. The sunrise model: a contribution to the teaching of nursing consultation in collective health. Am J Nurs Res[lnternet]. 2013[cited 2017 Jan 15];1(1):20-23. Available from: http://pubs.sciepub.com/ajnr/1/1/3/

7. Moraes EM. Atenção à saúde do idoso: aspectos conceituais. Brasília: Organização Pan-Americana da Saúde; 2012.

8. Fernandes MGM, Garcia TR. Tension attributes of the Family caregiver of frail older adults. Rev Esc Enferm USP [Internet]. 2009[cited 2017 Jan 20];43(4):816-22. Available from: http://www.scielo.br/pdf/reeusp/v43n4/en_a12v43n4.pdf

9. Silva RMFM, Santana RF. Diagnóstico de enfermagem "tensão do papel de cuidador": revisão integrativa. Rev Bras Geriatr Gerontol[Internet]. 2014[cited 2017 Jan 10];17(4):887-96. Available from: http://www.scielo.br/pdf/rbgg/v17n4/1809-9823rbgg-17-04-00887.pdf

10. Pedreira LC, Oliveira AMS. Cuidadores de idosos dependentes no domicílio: mudanças nas relações familiares. Rev Bras Enferm [Internet]. 2012[cited 2017 Jan 15];65(5):730-6. Available from: http://www.scielo.br/pdf/reben/v65n5/03.pdf

11. Gratão ACM, Vendruscolo TRP, Talmelli LFS, Figueiredo LC, Santos JLF, Rodrigues RAP. Burden and the emotional distress in caregivers of elderly individuals. Texto Contexto Enferm [Internet]. 2012[cited 2017 Jan 15];21(2):304-12. Available from: http:// www.scielo.br/pdf/tce/v21n2/en_a07v21n2.pdf

12. Strauss A, Corbin J. Pesquisa qualitativa: técnicas e procedimentos para o desenvolvimento de teoria fundamentada. 2. ed. Porto Alegre: Artmed; 2008.

13. Duarte YAO, Andrade CL, Lebrão ML. O índex de Katz na avaliação da funcionalidade dos idosos. Rev Esc Enferm USP[Internet]. 2007[cited 2017 Jan 15];41(2):317-25. Available from: http://www.scielo.br/pdf/reeusp/v41n2/20.pdf

14. Scazufca M. Brazilian version of the Burden Interview Scale for the assessment of care in careers of people with mental illnesses. Rev Bras Psiquiatr[Internet]. 2002[cited 2017 Jan 10];24(1):12-7. Available from: http://www.scielo.br/pdf/rbp/v24n1/11308.pdf

15. Mari JJ, Williams P. A validity study of a psychiatric screening questionnaire (SRQ-20) in primary care in the city of São Paulo. Bras J Psychiatry [Internet]. 1986[cited 2014 Apr 10];148:23-6. Available from: https://www.ncbi.nlm.nih.gov/pubmed/3955316

16. Couto AM, Castro EAB, Caldas CP. Experiences to be a family caregiver of dependent elderly in the home environment. Rev Rene[Internet]. 2016[cited 2017 Jan 15];17(1):76-85. Available from: http://www.revistarene.ufc.br/revista/index.php/revista/ article/view/2204/pdf 1

17. Oliveira DC, D’elboux MJ. Estudos nacionais sobre cuidadores familiares de idosos: revisão integrativa. Rev Bras Enferm [Internet]. 2012[cited 2017 Jan 15];65(5):829-38. Available from: http://www.scielo.br/pdf/reben/v65n5/17.pdf

18. Seima MD, Lenardt MH, Caldas CP. Relação no cuidado entre o cuidador familiar e o idoso com Alzheimer. Rev Bras Enferm [Internet]. 2014[cited 2017 Jan 20];67(2):233-40. Available from: http://www.scielo.br/pdf/reben/v67n2/0034-7167reben-67-02-0233.pdf

19. Oliveira BC, Garanhani ML, Garanhani MR. Caregivers of people with stroke: needs, feelings and guidelines provided. Acta Paul Enferm [Internet]. 2011[cited 2017 Jan 20];24(1):43-9. Available from: http://www.scielo.br/pdf/ape/v24n1/en v24n1a06.pdf

20. Carvalho DP, Toso BRGO, Viera CS, Garanhani ML, Rodrigues RM, Ribeiro LFC. Caregivers and implications for home care. Texto Contexto Enferm[Internet]. 2015[cited 2017 Jan 15];24(2):450-8. Available from: http://www.scielo.br/pdf/tce/v24n2/0104-0707tce-24-02-00450.pdf

21. Costa SRD, Castro EAB. Autocuidado do cuidador familiar de adulto ou idoso dependente após a alta hospitalar. Rev Bras Enferm [Internet]. 2014[cited 2017 Jan 20];67(6):979-86. Available from: http://www.scielo.br/pdf/reben/v67n6/0034-7167reben-67-06-0979.pdf

22. Herdman TH, Kamitsuru S. Diagnósticos de enfermagem da NANDA: definições e classificação 2015-2017. Porto Alegre: Artmed; 2015.

23. Loureiro LSN, Pereira MA, Fernandes MGM, Oliveira JS. Percepção de enfermeiras sobre a tensão do papel de cuidador. Rev Baiana Enferm[Internet]. 2015[cited 2017 Jan 15];29(2):164-71. Available from: https://portalseer.ufba.br/index.php/enfermagem/ article/view/12596/pdf_122 